\title{
A critical assessment of the NMC Horizon reports project
}

\author{
Sonja Grussendorf \\ London School of Economics and Political Science
}

\section{Introduction}

In February 2017, the New Media Consortium (NMC) published its fourteenth Horizon Report. Horizon Reports are the result of discussion and evaluation, by a panel of experts, of current trends in educational technologies. Based on their survey of the Educational Technology landscape, they predict which technologies are likely to become of value and/or established in the Higher Education sector over the next five years. These reports are popular among the learning technology community: many bloggers summarise the main findings year on year; they are cited in academic literature; they are used as benchmarks and evidential support to learning technology projects. They have become a mainstay resource and influence Educational Technology purchasing decisions - and, by implication, one might expect them to have influence on pedagogical ideas. For that reason, it is important that they come under some academic scrutiny, but there is surprisingly little critical engagement with them in academic literature. It is my intention to contribute to that engagement in some small way by critically examining these reports on three connected issues:

1. The issue of their influence on the educational technology community;

2. The issue of their forecasting practice;

3. The issue of their ideology.

The NMC claims that its reports are being downloaded in their millions, but the reports' actual influence may not be as wide-reaching as all that, because one might argue that downloading does not equal reading, and that reading does not equal agreement. If therefore the Horizon reports have relatively little influence on educational ideas, and on purchasing decisions, one might understand the lack of critical academic engagement with them. If the reports do have considerable reach however, then it is important that we do examine them critically, both about their nature, i.e. what they are, and about their intended purpose, i.e. what they are for.

In the first part, I will therefore look at the purported importance and possible influence the Horizon Project has or has had in the first place.

Secondly, Horizon Reports make predictions about the future. It is for that reason that the issue of their influence on the educational technology community matters. If they merely charted the Educational Technology landscape - to give practitioners a broad, perhaps global, context for their field - one might trust their 'objectivity', as long as their methodology were sound and open. However, if the Horizon Reports' major selling point is that they make predictions about the future, then the way that they are used by practitioners, and the way their predictions influence decision making, take on a further significance. I will, therefore, in 
the second part, explore to what extent their forecasting practice matters, especially with regard to accuracy.

Finally, forecasts aren't neutral observations, but rather the results of interpretations, which are ultimately based on subjective choices, and forecasts may have a strong underlying ideological bias. While we can accept that neutrally observed, descriptive, or 'factual' reports are used to make decisions on investments in Information Technology or Educational Technology, subjective forecasts - and I repeat my suggestion that forecasts are necessarily subjective - ought to be scrutinised more carefully. We should therefore set out to determine whether the NMC has any allegiances or dependencies and whether the reports subscribe to any particular ideology. Uncovering any such bias does not render the reports untenable or obsolete, but it should be part of good practice to make such bias explicit where it is implicit. In consequence, in the third part, I shall uncover some of the implicit bias inherent in those reports.

I shall begin by giving a short exposition of what the Horizon Reports are.

\section{Horizon Reports and the NMC: background}

Horizon Reports have been published since 2004. They are part of a continuing 'Horizon Project', initiated and run by the NMC, itself conceived in 1993 in order to bring together "a group of hardware manufacturers, software developers, and publishers who realised that the ultimate success of their multimedia-capable products depended upon their widespread acceptance by the higher education community in a way that had never been achieved before." (New Media Consortium 2017c).

The Horizon Reports set out to help educational 'thought leaders' make decisions about which types of educational technologies to pay attention to, which of them to use and in which systems to invest. They make forecasts about technologies that they suggest will have an impact on the global education sector.

According to the authors, the nature of their project is to "chart the landscape of emerging technologies for teaching, learning, and creative inquiry" (Johnson et al. 2011; Johnson et al. 2012; Johnson et al. 2013); they added, in 2015, that "with more than 13 years of research and publications, [the Horizon project] can be regarded as the world's longest-running exploration of emerging technology trends and uptake in education." (Johnson et al. 2015, p.1) The ultimate aim of all these publications, whether taken as a whole or taken individually is "to help educators and thought leaders across the world build upon the innovation happening at their institutions by providing them with expert research and analysis" (New Media Consortium 2017c). The NMC says that its research "uniquely provides a cross-sector view of disruptors in higher education, $\mathrm{K}-12$, academic \& research libraries, and museums" (New Media Consortium 2017b)

The reports are produced by means of a transparent iterative research method, a modified Delphi process, refined over the years. They are written by a large panel of experts, and "in any given year, a third of panel members [of experts] are new, ensuring a flow of fresh perspectives each year." (New Media Consortium 2017b) For every report, the evidence collection and discussions are openly accessible on a corresponding Horizon Report wiki. 


\section{The issue of influence and impact of Horizon Reports on the Educational Technology community}

The NMC Horizon Project prides itself - justifiably - on its openness of research, but it is not so easy to learn about its reach from its website. Thankfully, I received some email clarification from the NMC's former Senior Director of Publications and Communications, Samantha Becker ${ }^{1}$. She declared that there have been at least three million downloads in 195 countries of reports in their HE series from 2014-2017. Numbers are available only from 2014, when a data analytics' infrastructure was introduced. On an annual basis, sum downloads of all the reports since 2014 are between one and two million. The top five countries for downloads in the six months leading up to May 2017 - the time of my email exchange with Ms Becker - were, in descending order, the US, Australia, UK, China and Canada. Bearing in mind that downloading doesn't equal reading and that reading doesn't equal agreement, one might, on the basis of these numbers, justifiably assume that the reports have garnered a status of some global popularity. When further looking at citation numbers, one might also assume that they have garnered a status of some authority: for example, a Google Scholar search sets the citation number for the 2015 Higher Education edition of the Horizon Report alone at 807.

To determine how the reports were used in the literature, I sampled about forty articles from a pool of fifty-six articles in the British Journal of Educational Technology that contained references to any Horizon Reports from 2004-2017. It was apparent from my sample that the reports are on the whole used instrumentally, i.e. as trusted neutral instruments: as reference works, and/or as benchmarks against which the technology uptake of a country / a sector / an institution is measured, and as structural support and/or justification for embarking on specific learning technology research projects. For example, one article begins:

"As revealed by the recent Horizon Report (Johnson, Smith, Willis, Levine \& Haywood, 2011), the creation of gesture-based interfaces (e.g., Microsoft Kinect, Nintendo Wii and Apple iPhone/iPad) create promising opportunities for educators to offer students easier and more intuitive ways to interact with the content in multimedia learning environments than ever before." (Chang et al. 2013, my emphasis);

Another article uses the same report in the same context:

"In short, all these studies suggest that gestures enhance learning. In support of this assertion, the Horizon Report (Johnson, Smith, Willis, Levine \& Haywood, 2011) identified gesture-based computing as an emerging technology that has a great potential to influence education in the near future by providing a novel form of interaction, expression and activity" (Ozcelik and Sengul, 2012; my emphasis).

\footnotetext{
${ }^{1}$ In December 2017, it was announced, to general surprise, that the NMC had ceased operations. This was after a first draft of this article had been sent off. The NMC website has not been updated since NMC cessation of operations. For the purposes of this article this does not matter, as it deals with the Horizon reports up to February 2017. It is nevertheless a surprising and sad turn of events, not least for the NMC staff.
} 
The reports are thus treated as expert data, or objective reference works:

"The NMC Horizon Report (Johnson, Adams, \& Cummins, 2012) identified mobile apps, smartphones and tablet computers as trending tools for active learning in classrooms with a time-to-adoption horizon of one year or less." (Van Daele et al. 2017, my emphasis)

and

"Indeed social media has been seen as a major driver for change in higher education in the 2014 New Media Consortium Horizons report (NMC, 2014) and improvement of digital literacy skills has been reported as a major challenge in the 2015 report (NMC, 2015)." (Purvis, Rodger and Beckingham, 2016; my emphasis)

These are representative of the type of engagement the Horizon reports meet with in the literature: relied on as supporting evidence, yes; questioned and analysed critically, no. One article that engages explicitly with the Horizon Reports in terms of their forecasting accuracy is New technology trends in education: Seven years of forecasts and convergence (Martin et al. 2011) It contains a bibliometric analysis of the predictions and concludes that the reports are well suited for "meta-trends analysis of technologies likely to impact education." (Martin et al. 2011, p.1905). The authors focus on the success or failure of Horizon Report forecasts, but they do not discuss the desirability of such forecasting. Nor do they discuss the impact that the reports have in promoting some technologies over others, or the bias that this implies and promotes. I have given here only a snapshot of the literature, but the snapshot is representative of the academic treatment the reports have received so far. Most of the sampled papers and books cite the reports, but do not discuss them. This suggests that they are viewed as trustworthy neutral sources of impartial information.

So far, I have established that the Horizon Reports feature heavily in the literature as neutral reference works, but this does not in itself mean that they also influence 'thought leaders' directly. Yet, owing to their popularity and the singular uniqueness of the project, it is likely that they do. And it does mean that academics in the learning technology discipline regard them, and rely on them, uncritically, which makes it unlikely that policy makers view them any more critically. I conducted a short opinion survey to see if the Horizon Report is as prominent in real life as it is in the literature. The sample is not representative, but offers a larger anecdotal basis for determining how the reports are received and used in the community of Educational Technology practitioners (and 'thought leaders'). The survey was sent to various email network lists of learning technologists, heads of eLearning and HE sector IT departments, from which participants self-selected. Eighty-one respondents participated. Thirteen participants stated unfamiliarity with the Horizon Report, which ended the survey for them. Three respondents did not answer any questions after having stated familiarity with the Horizon Report. One respondent did not answer any further questions after stating that they did not read them as a priority. This left sixty-four respondents who answered the majority of the survey questions.

The purpose of the survey was to inquire into three related areas, a) how participants read the Horizon Reports and b) how participants thought the Horizon Reports influenced their understanding of the Educational Technology landscape and c) how, if at all, they felt that their own views were represented in the Horizon reports. 
The following short summary is for the sixty-four respondents who answered the majority of the survey.

Asked to classify how regularly the respondents read the reports,

- Forty-one read them regularly, seventeen read them occasionally when they remember it, five do not think of them as a priority and one person chose "other", qualifying their answer with "It is on my radar, and sometimes I look at it to remind myself how typically annoying such reports are".

Asked to classify how much they read the reports

- Thirty-three chose the statement "Executively: I read the summary and some of the predicted technologies", twenty-two chose the statement "Fully: I read as much of the report as I can", eight chose "Concisely: I skim the headline predictions in the content table" and one chose "By proxy: I read/ hear about it elsewhere".

Asked to choose reasons for reading the reports, respondents chose as follows (this question allowed for multiple answers):

- Fifty-six respondents chose "Horizon scanning" as a reason, forty-three chose 'it is directly relevant to my job', twenty-nine agreed that it provides them with a global baselined, and twenty-seven agreed that they read the reports to aid them in strategic decisions about educational technology. Nineteen respondents also agreed that the reports had descriptive accuracy for which they read them and sixteen that the reports' predictive accuracy had value to them.

Asked whether the descriptions and predictions contained in the Horizon report influenced their thinking about Educational Technology,

- Thirty-five chose to answer with yes, sixteen were not sure and twelve said that it was not. One person did not answer this question.

Asked whether the descriptions and predictions contained in the Horizon report influenced their strategic decisions about adopting particular Educational Technologies,

- Thirty chose to answer with yes, eighteen chose to answer with no, and sixteen were not sure.

Asked if the descriptions and predictions contained in the Horizon report reflected how respondents think about educational technology,

- Twenty-five respondents chose to answer with yes, twenty-nine were not sure and ten respondents chose to answer no.

Asked if the descriptions and predictions contained in the Horizon report reflected their strategic decision making about educational technology,

- Twenty-seven respondents opted to say they were not sure, twenty-two chose to answer with yes and fourteen respondents chose to answer with no. One person did not answer this question. 
In this short poll, respondents were more likely to believe that their thinking was influenced by the reports than they believed that their opinions were reflected in the reports. This brings us to a point about the reports' methodological intentions. Horizon Reports are supposedly put together by an expert of panels who listen to the opinions of the sector. The NMC explains that the panel of experts brought together each year for each annual report "as a whole is intended to represent a wide range of backgrounds, nationalities, and interests, yet each member brings a particularly relevant expertise." (New Media Consortium 2017a). In the above short survey, respondents were either unsure or did not feel that their views were being taken on board by the Horizon reports. However, my participants were almost exclusively from the UK, whereas the Horizon Project panels tend to be populated by experts from the USA. Any discrepancy might be explained by this difference. Then again, the NMC points to its reports' global reach and global impact, and we should therefore point out that there might be some cultural and geographical bias in them. The USA Higher Education system differs significantly from those of the UK and Europe. UK and/ European readers of the report will need to consider that some of the technologies that are predicted to make an impact within a USA context, and that such predictions are not so easily translatable into their own context.

So far, I have argued that the reports are used extensively as neutral reference works and have received very little critical attention in the literature. Judging from a small sample of UK practitioners we might further suggest that the reports are read strategically, rather than critically, above all for horizon-scanning and because they are directly relevant to their jobs, and that the reports have some influence on their strategic decision making with regards to using technologies for learning. Thus, the reports have established themselves as a trusted source of information and potentially form the basis for financial decision-making in the sector, without having been scrutinised for their methods and processes, their neutrality or even their forecast accuracy. In the next part, I will deal with the matter of their forecasting practice.

\section{The issue of the Horizon Reports' forecasting practice}

The Horizon Reports' first aim is to chart "the landscape of emerging technologies", but, based on this, they also make predictions about the future. Commenting on the eighth annual report, Stephen Downes complained: "in my opinion, the Horizon Report tracks technologies that have become more prevalent in media reports. It is a publicity tracker, not a tech tracker." (Downes, 2011; my emphasis). I am not sure that this is entirely fair, because if the panels of experts are to track emerging technologies, they need to have heard about them. The Horizon Report expert panels explicitly track the cultural Educational Technology landscape, naturally technologies which receive most publicity feature most prominently on that landscape. I would suggest that, owing to their popularity, Horizon Reports have become publicity generators, adding to the hype and promotion of their selected technologies or technology trends. Predictions by a well-regarded, and (selfproclaimed) unique authoritative source can act as self-fulfilling prophecies. The six technologies that the panel of experts pick each year are not merely predicted to make an impact; rather, by the very fact of their being predicted, they become recommended. Which emerging technology company would not want to be recommended by such an influential publication? 
I have asserted that the Horizon Reports have somehow escaped academic scrutiny, but, naturally, they have also attracted critical comments in the past. Most frequently, their methodology is criticised. Stephen Downes' is one such critical voice, because he considers the methodology not to be based on a "deep knowledge [of] significant technology developments." (Downes 2015). Audrey Watters has focused her criticism on the lack of historical perspective, stating as one of her "frustrations with the project: it does not revisit previous year's predictions, and as such does not really explain how or why the trends suddenly appear and disappear and reappear..." (Watters 2015). But both these criticisms appear merely in short blog posts - and neither of them has a problem with technology predictions as such. I would suggest that a more important issue about forecasting is that it is always liable to bias, because forecast methods are subject to bias - sample bias, startingpoint bias, ideological bias and so on. Yet these forecasts are often presented as hard evidence, and they are read and used as providing and being exactly that. For example, a judgmental forecasting method like the Delphi method, which relies on the judgement of a large set of experts, needs to be scrutinised for the criteria for assembly of the expert panel.

One of the few properly engaging, critical analyses of the Horizon Reports I have been able to find is When prophecy fails by John Baggaley (Baggaley 2013). In his article, he describes with brilliant clarity, and with great force, the negative fallout of inaccurate predictions. He castigates projects such as the Horizon Report and the 'One laptop per child' initiative because of their flawed methodology and their hyperbolic claims of the positive effects of educational technology on, in particular, developing countries.

Baggaley wants us to be aware of the real dangers of applying future-gazing speculations to real-life situations, especially if applying forecasts out of their first-world, privileged context:

"Predictions about emerging technologies play a useful role in alerting educators to new possibilities. But the history of the field is littered with uncritical stargazing, and well-designed media are left to rot like dinosaurs on the landscape owing to baseless promises that new media will improve on them. Abandoning technologies that do the job well in favor of unproven ones can set the field and the students back by years." (Baggaley 2013, p.125).

Baggaley means that the prediction-makers, even if they do not care about their predictions' accuracy, are still responsible for potential negative fall-out. One could argue that each Horizon report is only a snapshot of expert opinion at the time of their conception, and that the NMC makes no claim to have envisaged the project to be a longitudinal analysis. But even if the Horizon report project was not intended as a longitudinal analysis from the outset, the authors accept it as exactly that in the 2015 Higher Education edition, by stating that "with more than 13 years of research and publications, [the Horizon Project] can be regarded as the world's longest-running exploration of emerging technology trends and uptake in education." (Johnson et al. 2015).

But perhaps it does not matter whether forecasts are accurate or not, perhaps what matters more is why forecasts are being made at all. I suggest that we should question the motivation for making such predictions in the first place. Predictive reports are, in some way, always about the present. Like science fiction, they do not deal with the future, which is in any case impossible, but they reveal the now. What matters is that the now creates the future. For this reason, John Baggaley raises the point that predictions can be irresponsible. 
Predictions made by an authoritative source can cause investors to ignore present solutions because they are always waiting for the future.

For this reason, we must focus our attention not on when and how the reports have 'failed' in their crystal-gazing: I want to bring us back to asking why they might engage in this crystalgazing in the first place. What benefit is there to making such predictions? Further, who benefits from such predictions? Above, I have already intimated that the Horizon reports garner publicity for the technologies they discuss and, in some way, recommend. In a private email, Samantha Becker, the NMC Senior Director of Communications (who was then also the Director of the Horizon Project) wrote to me that "Once we release a report, I like to say 'it belongs to the people.' Any conversations it incites, positive or negative, is a beautiful thing because it's getting people talking and questioning about pressing issues in education." This is a generous sentiment and she further elucidates: "we strive for the reports to be completely neutral and unbiased. The NMC staff never selects the topics - an outside expert panel does upon months of discussion and voting." This is undoubtedly true, but it is not the whole truth. Baggaley observes that access to the panel is provided by membership to the NMC, and corporate members include Adobe, Apple, Pearson, corporations for whom the education sector is a significant market. Thus, at least some people on the editorial board have vested financial interests in technologies being used in Higher Education. In that context, the composition of the panel matters, and so does the chosen method. The Delphi process is designed for the building of consensus - a wonderful thing, unless it means that it methodically irons out fringe views, where such fringe views might be determined by one's nationality. For example, a German academic working and reading in a German Higher Education context, will necessarily be at the fringes of a panel whose middle ground is populated by Americans. By that same reckoning, an academic might find herself or himself at the fringes in a panel dominated by corporate types. And here we might return to what we know about the origins of the NMC, namely that it was explicitly put together so that a group of technology corporations could open the Higher Education sector to their products. In other words, the NMC's raison d'être is to "sell us stuff".

\section{The issue of the underlying ideology of the Horizon Reports}

The group consisted of Apple Computer, Adobe Systems, Macromedia, and Sony, companies still well-known, though perhaps not primarily for their philanthropic endeavours. I cannot here enter a discussion about whether or not private for-profit companies can have benign or educationally-beneficial motives. I can say that the NMC subscribes to a positive technological instrumentalism, that is, its implicit assumption is that technology is always better, that it is always progressive and that it has intrinsic positive value. That is a perfectly legitimate position to hold, albeit not a particularly differentiated one. It is tenable, however, and allows for the possibility that the consortium's motivation for making its products useful to the education sector is not merely profit-motivated. Thus, whilst the consortium members banded together the better to sell their products to the Higher Education sector, it might also have benefited that sector. And so, though we might be suspicious of the origins of the NMC, we do not need to conclude that their research is deliberately biased. We do need to be vigilant. At least their data is open, and so they are justified to claim in their Research and Publication Standards: 
"We are committed to contributing to the body of knowledge that informs practice and drives innovation through conducting independent research and publishing unbiased reports and other resources ..." (New Media Consortium 2017d)

We can be generous and grant them their commitment to research that is neutral, objective, and agenda-free. We don't have to take for granted that they succeed. As for their independence, I would suggest that my earlier point - that NMC membership guarantees access to the expert panel - puts this into doubt. There are also other ways in which bias shows. For example, I mentioned that the NMC clearly subscribes to a positive and instrumental view of technology. Such a view expresses an ideology and it gives rise to ideological bias, of which there are plenty of implicit instances. Thus, in the 2014 report, the authors state that because "students expect to graduate into gainful employment, [i]nstitutions have a responsibility to deliver deeper, active learning experiences and skillsbased training that integrate technology in meaningful ways." (Johnson et al. 2014) This implies that, for the authors, the responsibility of universities is to deliver students ready for the labour market. It begs the question 'What are universities for?' quite clearly: universities are places of vocational training. However, that is not the only answer and it is not everybody's answer; it is an answer specific to a specific educational viewpoint - an ideology. In the 2017 report, the theme of 'spurring innovation' is introduced by this clause: "if education is viewed as a vehicle for advancing the global economy...". This too, begs the question of what education is for, this time implying that it is to advance the global economy. It is possible to find such hidden unchallenged assumptions throughout the reports from 2004 till now and I will add two further examples. In the 2009 report, the executive summary states that "Higher education is facing a growing expectation to deliver services, content and media to mobile and personal devices." and "The renewed emphasis on collaborative learning is pushing the educational community to develop new forms of interaction and assessment." (Johnson et al. 2009).

It does not matter if these are statements that one agrees with, or that they reflect an agreeable or disagreeable idea. What matters is that both statements carry hidden assumptions that are not 'neutral'. The first quotation implies that, when there is a growing expectation to deliver a service, the answer must be to fulfil the expectation, rather than to question it. That, however, is not always the best or only option available. It is not the only answer and it is not everybody's answer. The second quotation implies that collaborative learning is educationally valuable. This too can and should be questioned. Maybe it is, and maybe it isn't. I would suggest that at least it is not exclusively so: in Higher Education, solitary learning is also important, useful and encouraged, but we find no mention of this in the reports. It just so happens that the technological trend is towards social working, collaboration, networking. One might wonder to what extent we have 'renewed emphasis' on collaborative learning because of the explosion of social media over the last decade, rather than because demonstrable improvements in learning drive the development of social tools. One might also wonder to what degree that is down to bands of commercial enterprises such as the New Media Consortium. Above all, it matters that within the context of the Horizon Report these are 'factually reported' but not critically discussed. It matters, because it is rightfully academic that we approach these and many other assumptions critically and ask critical questions. We understand now that the NMC's answer to any of our educational challenges is to utilise technology to meet them. Disagreeing with such technological determinism does not necessarily force us to shun the outcomes of the reports. The 
suggestions made by the reports can remain useful to us, but we should approach them critically. That, I would suggest, would be to our students' and our own advantage; it would be to the advantage of learning, teaching and research, rather than to the advantage of the companies who initiated, more than twenty years ago, a consortium that has as its explicit aim the embedding of its technologies into our sector.

\section{Reference list}

Baggaley, J., 2013. When prophecy fails. Distance Education, 34(1), pp.119-128.

Chang, C.-Y. et al., 2013. Embodying gesture-based multimedia to improve learning. British Journal of Educational Technology, 44(1), pp.E5-E9.

Van Daele, T., Frijns, C. \& Lievens, J., 2017. How do students and lecturers experience the interactive use of handheld technology in large enrolment courses? British Journal of Educational Technology, 48(6), pp.1318-1329.

Downes, S., 2011. Stephen's Web Crib sheet for 2011 Educase Horizon Report Stephen Downes. Blog. Available at: http://www.downes.ca/post/54807 [Accessed October 26, 2017].

Downes, S., 2015. Stephen's Web NMC Horizon Report: 2015 Higher Education Edition Stephen Downes. Stephen Downes (blog). Available at: http://www.downes.ca/post/63412 [Accessed October 24, 2017].

Johnson, L. et al., 2013. NMC Horizon Report: 2013 Higher Education Edition, Austin, Texas: New Media Consortium.

Johnson, L. et al., 2014. NMC Horizon Report: 2014 Higher Education Edition, Austin, Texas: New Media Consortium.

Johnson, L. et al., 2015. NMC Horizon Report: 2015 Higher Education Edition, Austin, Texas.

Johnson, L. et al., 2011. The 2011 Horizon Report, Austin, Texas: The New Media Consortium.

Johnson, L., Adams, S. \& Cummins, M., 2012. The NMC Horizon Report: 2012 Higher Education Edition, Austin, Texas: The New Media Consortium.

Johnson, L., Levine, A. \& Smith, R., 2009. The Horizon Report 2009, Austin, Texas: The New Media Consortium.

Martin, S. et al., 2011. New technology trends in education: Seven years of forecasts and convergence. Computers \& Education, 57(3), pp.1893-1906.

New Media Consortium, 2017a. 2017 Horizon Report Wiki - Methodology. Horizon Wiki Methodology. Available at: http://horizon.wiki.nmc.org/Methodology [Accessed May 5, 2017]. New Media Consortium, 2017b. NMC Horizon | The New Media Consortium. NMC Horizon 
Project. Available at: https://www.nmc.org/nmc-horizon/ [Accessed October 30, 2017].

New Media Consortium, 2017c. NMC Horizon Project History | The New Media Consortium. The Horizon Project webpages. Available at: https://www.nmc.org/nmc-horizon/nmc-horizonproject-history/ [Accessed May 5, 2017].

New Media Consortium, 2017d. NMC research and publication standards. NMC webpages.

Ozcelik, E. \& Sengul, G., 2012. Gesture-based interaction for learning: time to make the dream a reality. British Journal of Educational Technology, 43(3), pp.E86-E89.

Purvis, A., Rodger, H. \& Beckingham, S., 2016. Engagement or distraction: the use of social media for learning in higher education. Student Engagement and Experience Journal, 5(1), p.6.

Watters, A., 2015. The Horizon Report: A History of Ed-Tech Predictions. Hack Education Blog. Available at: http://hackeducation.com/2015/02/17/horizon [Accessed October 24, 2017]. 